\title{
A study on perceived social support and self esteem in children with and without learning disability
}

\author{
Kshipra Rahul Pathrikar ${ }^{1}$ \\ ${ }^{1}$ Post graduate student, Department of Psychology, Maniben Nanavati Women’s College, Mumbai. \\ E-mail - kshiprapathrikar@gmail.com
}

\begin{abstract}
Background: Learning disability is an invisible disability and social support plays a vital role in the development of the child with learning disability. The purpose of the study was to investigate the perceived social support and self- esteem of children with and without learning disabilities.

Methodology: Self- report data were collected from 120 children by using multidimensional perceived social support scale and Rosenberg's self-esteem scale. The data was then analyzed statistically and the results were presented.

Results: From 120 children, 60 children were diagnosed and certified with learning disabilities and 60 children were without learning disabilities. Participants' ages ranged from $10-14$ years. It was hypothesized that children with learning disability would report lower levels of perceived social support and self- esteem than compared to children without learning disability. It was also expected that girls would report lower scores than boys on both the dependent variables. Multivariate analyses of group differences revealed that there was an effect of learning disability on perceived social support, whereas there was no effect of learning disability on self-esteem. It also revealed that there was no effect of the interaction of gender and group (i.e. children with learning disability and children without learning disability) on perceived social support and self-esteem.

Conclusion: Social support and self esteem are important variables in the progress of child with learning disability and needs further exploration and research.
\end{abstract}

ABSTRACT

Key words: learning disability, social support, self esteem, Rosenberg self esteem scale, perceived social support scale.

(Paper received $-10^{\text {th }}$ May 2016, Peer review completed $-12^{\text {th }}$ July 2016, Accepted $-28^{\text {th }}$ July 2016)

\section{INTRODUCTION}

The term, learning disability (LD) is a non-specific classification for persons with severe learning difficulties who are eligible for placement in special education. Persons with learning disabilities have specific and severe impairments in one or more of the following areas: comprehension, spelling, and articulation [1]. The DSM IV classification [2] had placed an individual's learning disorder into one of three categories - Specific Reading Disorder, Specific Math Disorder and Disorders of Written Expression. The DSM 5 [3] has revised the diagnosis into a single category, Specific Learning Disorder, which captures the overall difficulty experienced in the academic domain; allowing the diagnostician to specify the details of the areas of academic impairment as well as the severity of the disorder: mild, moderate or severe. LD typically occurs in individuals identified as having normal intelligence, although it may also occur in individuals identified as gifted. Despite the level of measured intelligence, the individual persists in having difficulties learning and using academic skills. LD also can affect an individual's adaptive skills across the lifespan. Difficulties with relationships, overall poorer mental health and higher rates of unemployment are some characteristics associated with LD [4]. 


\section{Learning Disability and perceived social support}

Perceived social support in students with learning disabilities has been studied as a mediating variable in self-concept [5]. Studies have reported that the global self-concept of students with learning disabilities can be accounted for by perceived support from significant others such as teachers, parents, friends, and peers [6]. Kashani and colleagues [7] examined the relationship between two elements of social support: the number of people listed as supportive and the level of satisfaction with that support. Results showed that children who reported less satisfaction with their social support system were more likely to be described as withdrawn by their teachers.

\section{Learning Disability and self esteem}

The term self-esteem is used to describe a person's overall sense of self-worth or personal value. Selfesteem is usually broadly defined as a person's overall evaluation of, or attitude toward, her- or himself [8]. Children with learning disability often struggle to develop and maintain high self-esteem. Children with low self-esteem may not believe they are worthy of good treatment. Because they feel this way, they may not ask for help or stand up for themselves. In other words, they don't develop self-advocacy skills. Children with low self-esteem may have trouble gaining the confidence they need to face and deal with their learning and attention issues. This is a lack of what's often referred to as "self-awareness" [9]. Previous studies have examined aspects of perceived social support and self- esteem in association with learning disabilities, but there is limited research on these variables in relation with Indian children having learning disabilities.

\section{Perceived Social Support}

The term social support is the perception that one is cared for, has assistance available from other people, and that one is part of a supportive social network [10]. Social support can come from a variety of sources, including family, friends, romantic partners, pets, community ties, and coworkers.

In a study of self-perception of worth, perceived social and emotional functioning by Martínez [11], young adolescents in middle school with different types of learning disabilities and a group with no learning disability were examined. The result revealed that the both the groups did not differ on global self-worth; whereas, girls reported lower global self- worth than boys. While students in the LD group rated their intellectual and academic self-worth lower than students in the other groups. Girls also reported lower intellectual self-concept than boys. No group or gender difference was found on non-academic selfconcept. Students with LD reported lower parent and friend support than compared to students with no learning disability. A study conducted by Dyson [12] indicated that fathers and mothers of children with developmental disabilities did not differ from each other: nor from fathers and mothers of children without disabilities in parental stress, family social support, or family function. However, parents of children with disabilities experienced a disproportionately greater level of stress relating to their children than did those of children without disabilities.

\section{Self-Esteem}

Self-esteem is a positive or negative orientation toward oneself; an overall evaluation of one's worth or value. Self-esteem is only one component of the self-concept, which Rosenberg defines as "totality of the individual's thoughts and feelings with reference to himself as an object" [13].

In a study of learning disability by Cosden [14], self-understanding and self- esteem of these children were studied. The result showed that increased knowledge about LD was not associated with higher self-esteem. It also showed that understanding of one's LD was associated with actual and perceived scholastic competence, while global self-esteem was associated with perceptions of competence in nonacademic domains.

The purpose of this study is to investigate the perceived social support and self-esteem of children with learning disabilities and without learning disabilities. Further, the aim of the study is to also see if gender plays a role in the level of perceived social support and self-esteem of the children with learning disabilities and children without learning disabilities. 


\section{METHODOLOGY}

\section{Sample and Procedure}

Self-report data were collected from children with learning disability and without learning disability who were between the age group of 10 to 14 years. These participants were selected by confirming their diagnosis with a learning disability certificate and their academic background from various institutes such as hospitals, schools and NGOs. Children who were willing to participate were given a consent form, which was signed either by their parents or teachers. The participants were then given a brief instruction and description of the study and then the questionnaire were given to the participants. This study was a $2 \mathrm{X} 2$ between subjects factorial design, as the independent variable: type of children has two levels (with learning disability and without learning disability) and gender has two levels (male and female). The data on all the measures were collected on the same day from the participants. Once all the data was coded and entered in excel sheet, descriptive statistic, test for normality, correlation and MANOVA was conducted of the scale items i.e. score obtained on perceived social support and scores obtained on self-esteem.

\section{Instruments}

\section{Perceived Social Support}

Multidimensional Scale of Perceived Social Support [15] measures the social support through self-report technique. The MSPSS measures three subscales, each addressing a different source of support, were identified and found to have strong factorial validity: (a) Family, (b) Friends and (c) Significant other.

\section{Self-Esteem}

Rosenberg Self- Esteem Scale [13] is a ten item Likert Scale with items answered on a four-point scalefrom strongly agree to strongly disagree.

\section{RESULTS}

All analyses were performed with the Statistical Package for the Social Sciences software (SPSS 22.0). Descriptive statistics (i.e. Mean, standard deviation, Skewness and Kurtosis) relating to subjects score on Perceived Social Support and score on Self-Esteem were computed first.

In this group of 120 students, the mean score for Perceived social support was $54.64(\mathrm{SD}=16.275)$. The maximum score on Perceived Social Support was 84 and the minimum score was 17. The mean score for Self- Esteem was $16.30(\mathrm{SD}=4.160)$. The maximum score on Self-Esteem was 26 and the minimum score was 9.

\section{MANOVA}

Multivariate analysis of variance (MANOVA) was the statistical procedure of choice for the current analyses. The general purpose of multivariate analysis of variance (MANOVA) is to determine whether multiple levels of independent variables on their own or in combination with one another have an effect on the dependent variables. Prior to conducting the multivariate analyses, the data were analyzed to determine if the assumptions for MANOVA were in place

Table 1: Showing correlation between the variables

\begin{tabular}{|l|l|l|}
\hline Measures & Score on PSS & Score on SE \\
\hline PSS & - & $.337^{* *}$ \\
\hline SE & $.337^{* *}$ & - \\
\hline \multicolumn{2}{|l|}{} \\
\hline
\end{tabular}

Wilks' lambda demonstrates the amount of variance accounted for in the dependent variable by the independent variable; i.e. the smaller the value, the larger the difference between the groups being analyzed. To interpret the data Wilk's Lambda was used as Wilks' lambda performs, in the multivariate setting, with a combination of dependent variables, the same role as the F-test performs in one-way analysis of variance, which makes it easier to calculate the P-value. 
Table 2: Showing results of multivariate test

\begin{tabular}{|l|l|l|l|l|l|}
\hline Effect & Value & $\mathrm{F}$ & $\begin{array}{l}\text { Hypothesis } \\
\mathrm{df}\end{array}$ & Error df & Significance \\
\hline Intercept & 0.044 & $1252.617^{\mathrm{b}}$ & 2 & 115 & 0 \\
\hline Ld_code & 0.774 & $16.794^{\mathrm{b}}$ & 2 & 115 & 0 \\
\hline Gender & 0.997 & $.190^{\mathrm{b}}$ & 2 & 115 & 0.827 \\
\hline Ld_code * Gender & 0.986 & $.817^{\mathrm{b}}$ & 2 & 115 & 0.444 \\
\hline $\begin{array}{l}\text { a. Design: Intercept + Ld_code }+ \text { Gender }+ \text { Ld_code }^{*} \text { Gender } \\
\text { b. Exact statistic }\end{array}$
\end{tabular}

With reference to table 2, MANOVA revealed a significant effect for LD code i.e. children with learning disability and children without learning disability (Wilks' Lambda) $[F(2,115)=16.79, p=0.0001]$. There was no significant multivariate effect on gender $[F(2,115)=0.190, N S]$. There was no significant multivariate effect for the interaction between learning disability code i.e. children with learning disability and children without learning disability and gender $[\mathrm{F}(2,115)=0.817$, NS $]$.

\begin{tabular}{|c|c|c|c|c|c|}
\hline Source & $\begin{array}{l}\text { Type III } \\
\text { Sum of } \\
\text { Squares }\end{array}$ & $\mathrm{df}$ & $\begin{array}{l}\text { Mean } \\
\text { Square }\end{array}$ & $\mathrm{F}$ & Sig. \\
\hline \multirow[t]{2}{*}{ Intercept } & 358285.41 & 1 & 358285.41 & 1654.98 & 0.00 \\
\hline & 31882.80 & 1 & 31882.80 & 1820.86 & 0.00 \\
\hline \multirow[t]{2}{*}{ Ld_code } & 6177.68 & 1 & 6177.68 & 28.54 & 0.00 \\
\hline & 0.30 & 1 & 0.30 & 0.02 & 0.90 \\
\hline \multirow[t]{2}{*}{ Gender } & 81.68 & 1 & 81.68 & 0.38 & 0.54 \\
\hline & 1.63 & 1 & 1.63 & 0.09 & 0.76 \\
\hline \multirow[t]{2}{*}{ Ld_code * Gender } & 147.41 & 1 & 147.41 & 0.68 & 0.41 \\
\hline & 26.13 & 1 & 26.13 & 1.49 & 0.22 \\
\hline \multirow[t]{2}{*}{ Error } & 25112.83 & 116 & 216.49 & & \\
\hline & 2031.13 & 116 & 17.51 & & \\
\hline \multirow[t]{2}{*}{ Total } & 389805.00 & 120 & & & \\
\hline & 33942.00 & 120 & & & \\
\hline \multirow[t]{2}{*}{ Corrected Total } & 31519.59 & 119 & & & \\
\hline & 2059.20 & 119 & & & \\
\hline \multicolumn{6}{|c|}{ a. $R$ Squared $=.203($ Adjusted $R$ Squared $=.183)$} \\
\hline \multicolumn{6}{|c|}{ b. $R$ Squared $=.014$ (Adjusted $R$ Squared $=-.012)$} \\
\hline
\end{tabular}

With reference to table 3, when looking at the main effects of the IV's on individual DV's MANOVA revealed a significant effect of LD code (i.e. children learning disability and children without learning disability) and Perceived Social Support $[F(1,116)=28.538, p=0.0001]$. There was no significant effect of LD code (i.e. children learning disability and children without learning disability) on Self- Esteem [F (1, $1160=0.17$, NS $]$. There was no significant effect of gender and Perceived Social Support $[F(1,116)=$ $0.377, \mathrm{NS}]$. There was no significant effect between Gender and Self- Esteem $[\mathrm{F}(1,116)=0.093$, ns]. Similarly, there was no significant effect between the interactions of LD code (i.e. children with learning 
disability and children without learning disability) and Gender on Perceived Social Support $[\mathrm{F}(1,116)=$ 0.681 , NS]. There was no significant effect between the interactions of LD code (i.e. children learning disability and children without learning disability) and Gender on Self- Esteem $[\mathrm{F}(1,116)=1.493$, NS $]$.

\section{DISCUSSION}

The primary goal of the study was to investigate perceived social support and self-esteem in children with learning disability and children without learning disability. To date, limited numbers of studies have been investigated to find out the effect of learning disability on perceived social support and self-esteem. The first hypothesis of the study stated that children with learning disability will have low perceived social support when compared to children without learning disability. From the result it can be seen that children with learning disability had lower perceived social support as compared to children without learning disability. The result was consistent with previous research by Martínez [1], which stated that children with learning disabilities have lower perceived social support i.e. they reported lower parent and friend support compared to students in the other groups. While collecting the data it was also observed that children without learning disabilities reported more of social support from friends and family as compared to children with learning disabilities. It was also observed that children with learning difficulties find it hard to share their problems with parents and friends. Few children with LD also reported that they were still able to share few problems with their parents than compared to their friends because they themselves feel that they don't have that much ability to compete with their friends.

The second hypothesis of the study stated that children with learning disability will have low self-esteem than compared to children without learning disability. From the results obtained it can be seen that children with learning disabilities were not low on self-esteem when compared to children without learning disabilities. The results were in line with a previous research by authors [16], which stated that individuals with learning disabilities are able to maintain a positive sense of global self-worth despite lower perception in academic domain. While collecting data it was found that children with learning disabilities rated themselves average on self-esteem, which was also same for children without learning disabilities. It was also seen that children with low perceived social support reported average self-esteem and some people with high or moderate perceived social support reported low self-esteem. This was seen in both the groups. When children with low perceived social were asked how they feel about themselves they reported that they feel very well confident about themselves and but sometimes they feel that they don't have that much ability as their classmate. This was finding was generally seen with LD children who were studying in normal schools. Children those who were studying in special schools with other LD children they reported moderate self-esteem and felt confident about them and also rated themselves equal to their classmates in abilities.

The third hypothesis stated that males with learning disabilities will score low on perceived social support than compared to females with learning disabilities. From the results obtained it can be seen that there was no effect of gender and learning disability on perceived social support as there was no interaction between gender and LD groups. The results were in line with a previous research by Martínez [1] who compare young adolescents in middle school with different types of learning disabilities and a group with no learning disability and examine their self-perceptions of worth, perceived social and emotional functioning. She found out there was no reported difference by group or gender on classmate, teacher, or general social support. While collecting data it was observed that females reported more of family support and males reported more of peer support. But the total scores on perceived social support between males and females were almost the same. Therefore, there was no difference between the scores of perceived social support on gender.

The fourth hypothesis of the study stated that males with learning disabilities will score low on self-esteem than compared to females with learning disabilities. From the results obtained it can be seen that there was no effect of gender and learning disabilities on self-esteem as there was no interaction between gender and 
LD groups. During data collection it was observed that children with LD and children without LD reported almost same amount of self-esteem regardless of their gender and group, which was not significantly proved. It was also observed that children with LD, male or female both had reported almost the same score on self-esteem, which was in line with the result of this study.

The overall finding of the studies indicates that children with learning disabilities scored low on perceived social support than compared to children without learning disabilities but when it came to self esteem both the groups (children with LD and children without LD) scored almost the same. It was observed that children without LD gave the highest rating to their friends on the perceived social support than compared to their families when they were asked about the same few students said that they find it comfortable to share with one of their parents rather than both and most of them reported that as both their parents are working they find it more comfortable to share all their problems with their friends. Similarly children with learning di76sabilities who parents are working have reported low perceived social support as well as low self-esteem than compared to children with LD who have only one parent working.

\section{Limitations and Research Implications}

Despite the strengths of the current study, there are several limitations that must be considered when interpreting these data. First, all dependent variables were based on self-report. Most of the children who were accompanied by their parents took help of their parents in filling up the data even after they were instructed that they have to rate themselves according to their point of view. Second limitation of the study was that all the data was not collected for one single institute. There were many institutes from which the data where collected and out of which few were carried out from some private school itself because of which it was observed that children with LD studying in normal school have low self-esteem than compared to other LD children who are studying in special schools and NGOs. Third limitation of the study was the time allotted to get a data sheet filled by each student from the institute. Some of the institutes allotted a very little time to interact with the students because of which less rapport was built and that affected the scores of those children, as they were scared to fill the questionnaire. Types of Learning Disabilities should also be taken into consideration when conduction further research.

\section{Implications for Practice}

From this study, we can say that children with Learning disabilities have almost same perceived social support and self-esteem than compared to children without Learning disabilities; whereas children with Learning Disabilities may account for poor level of psychosocial functioning than predicted. But from the ancillary observation it was observed that children with learning disabilities have lower perceived social support and self-esteem than compared to children without learning disabilities. Because having a learning disability is a salient part of the school experience of children and adolescents with LD, an examination of how students with LD feel about themselves, their social support networks, and their general psychological functioning is critical to understanding how their learning disability may act as an organizer of their emotional/psychological development. This study provides support for the notion that students with specific learning disabilities may struggle with specific psychosocial problems. The current research was conducted in an effort to increase attentiveness to the need for LD research and to begin a dialogue about support services that address each subtype's psychosocial needs.

\section{REFERENCES}

1. Martinez RS. A Comparison of Learning Disability Subtypes in Middle School: Self-concept, Perceived Social Support, and Emotional Functioning. Austin, Texas, Researh Dissertation, University of Texas ; 2002.

2. American Psychiatric Association. Diagnostic and Statistical Manual for the Classification of Psychiatric Disorders $-4^{\text {th }}$ edition. American Psychiatric Publishing ; 1994.

3. American Psychiatric Association. Diagnostic and Statistical Manual for the Classification of Psychiatric Disorders $-5^{\text {th }}$ edition. American Psychiatric Publishing ; 2013.

4. Martinez RS. Social support in inclusive middle schools: Perceptions of youth with learning disabilities. Psychol School 2006;43(2):197-209. 
5. Kloomok S, Cosden M. Self-concept in children with learning disabilities: The relationship between global self-concept, academic "discounting," nonacademic self-concept, and perceived social support. Learning Diasbil Quart 1994;17(2):140-53.

6. Forman EA. The effects of social support and school placement on the self-concept of LD students. Learning Disabil Quart 1988;11(2):115-24.

7. Kashani JH, Canfield LA, Borduin CM, Soltys SM. Perceived family and social support: Impact on children. J Am Acad Child Adolesc Psychiatry 1994;33(6):819-23.

8. Branden N. The Psychology of Self-Esteem. Bantam Press: New York; 1969.

9. Cunningham B. The Importance of Self-Esteem for Kids With Learning and Attention Issues. Retrieved from https://www.understood.org/en/friends-feelings/empowering-your-child/self-esteem/the-importanceof-self-esteem-for-kids-with-learning-and-attention-issues ; 2014.

10. Wills TA, Cohen S. Social support and interpersonal relationships. Prosoc Behav Rev Personal Soc Psychol 1991;12:265-89.

11. Tannock R. Rethinking learning disorders. Scientific American 2013;5.

12. Dyson LL. Fathers and Mothers of School-Age Children With Developmental Disabilities: Parental Stress, Family Functioning, and Social Support. Am J Mental Retard 1997;102(3):267-78.

13. Rosenberg M. Society and the adolescent self-image. Princeton, NJ: Princeton University Press ; 1965.

14. Cosden M, Elliott K, Noble S, Kelemen E. Self-understanding and self-esteem in children with learning disabilities. Learning Disabil Quart 1999;22:279-91.

15. Zimet GD, Dahlem NW, Zimet SG, Farley GK. The Multidimensional Scale of Perceived Social Support. J Personal Assess 1988;52:30-41.

16. Rothman HR, Cosden M. The relationship between self-perception of a learning disability and achievement, self-concept and social support. Learning Disabil Quart 1995;18(3):203-12.

$$
\begin{aligned}
& \text { Acknowledgements - Nil } \\
& \text { Source of Funding - Nil } \\
& \text { Conflict of Interest - Nil }
\end{aligned}
$$

